\title{
Enhancing the ENSO Predictability beyond the Spring Barrier
}

\author{
Han-Ching Chen ${ }^{1}$, Yu-Heng Tseng ${ }^{2 *}$, Zeng-Zhen $\mathrm{Hu}^{3}$ \& Ruiqiang Ding ${ }^{4}$ \\ El Niño-Southern Oscillation (ENSO) is the dominant interseasonal-interannual variability in the \\ tropical Pacific and substantial efforts have been dedicated to predicting its occurrence and variability \\ because of its extensive global impacts. However, ENSO predictability has been reduced in the $21^{\text {st }}$ \\ century, and the impact of extratropical atmosphere on the tropics has intensified during the past \\ 2 decades, making the ENSO more complicated and harder to predict. Here, by combining tropical \\ preconditions/ocean-atmosphere interaction with extratropical precursors, we provide a novel \\ approach to noticeably increase the ENSO prediction skill beyond the spring predictability barrier. The \\ success of increasing the prediction skill results mainly from the longer lead-time of the extratropical- \\ tropical ocean-to-atmosphere interaction process, especially for the first 2 decades of the $21^{\text {st }}$ century.
}

The El Niño-Southern Oscillation (ENSO) is the dominant interseasonal-interannual variability in the tropical Pacific and it exerts significant influence on weather and climate all over the world via atmospheric teleconnection $^{1}$. Because of its global influence on the atmosphere and oceans, ENSO directly affects worldwide human life and the terrestrial and marine ecosystems. Substantial efforts have been dedicated to developing different forecast approaches to predict ENSO evolution several seasons in advance ${ }^{2-5}$. Previous studies used the Warm Water Volume (WWV) along the equatorial Pacific as a key precursor of ENSO $^{6-9}$. However, WWV anomalies are not the only requirement for ENSO development ${ }^{1,10}$. It has been suggested that in addition to WWV condition, a series of westerly wind events/easterly wind surges (WWEs/EWSs) in the western-central Pacific play an important role in the onset and maintaining of ENSO events ${ }^{11-14}$.

Interestingly, the ENSO forecast skill was noticeably reduced after 2000 in terms of the correlation and root mean square error (RMSE) (e.g., failures of forecast in 2012/13 and 2014/15 are good examples; most models predicted a strong ENSO event but these years ended up with a neutral or a weak El Niño conditions). Consistently, the strength of the seasonal footprinting mechanism has intensified during the past 2 decades ${ }^{15}$. The footprinting mechanism can trigger central Pacific types of ENSO events via the subtropical ocean-atmosphere coupling ${ }^{16-20}$. The amplified footprinting mechanism makes the ENSO more complicated and harder to predict because of changes in ENSO frequency and magnitude in the $21^{\text {st }}$ century ${ }^{1,15}$. On interseasonal time scales, the spring predictability barrier (SPB) is still a large challenge that limits ENSO predictability, which tends to cause the model's forecasting skill to decrease sharply when the prediction is made through spring ${ }^{21,22}$.

Recently, some statistical models based on the concurrent tropical oceanic and atmospheric conditions have been used to predict ENSO evolution with skillful prediction ${ }^{23-25}$. These models outperformed some dynamic models and suggested key roles for subsurface heat content evolution together with the modulation of WWEs/ EWSs over the central Pacific to improve ENSO predictability compared to that solely based on the WWV. Although the equatorial atmosphere and ocean coupling is crucial in ENSO evolution, the prediction skill of ENSO is limited if the predictors are only confined to the tropical or subtropical Pacific Ocean ${ }^{1,26}$. ENSO evolution does not only rely on the tropical Pacific $\mathrm{c}^{23,27-29}$. Some studies have suggested that the extratropical Pacific sea level pressure (SLP) anomalies (SLPAs) during precedent winter over both the North and South Pacific, independent of the low-frequency WWV contribution, can modulate ENSO evolution via a footprinting-like mechanism $^{1,15-18,30}$. In addition, precursory signals from other oceans, such as the Atlantic and Indian Oceans, can also help to trigger ENSO events via atmospheric teleconnection ${ }^{31,32}$. Possible ENSO key predictors and their influencing routes are summarized in Fig. 1.

To enhance the reliability in predicting ENSO events, here we will include both tropical (WWV, WWEs/ EWSs) and extratropical factors and their interactions. Thus, a novel ENSO prediction model (EPM) combining the tropical status and extratropical ocean-atmosphere interaction is derived here to demonstrate the success in

${ }^{1}$ Department of Atmospheric Sciences, University of Hawaii at Manoa, Honolulu, USA. ${ }^{2}$ Institute of Oceanography, National Taiwan University, Taipei, Taiwan. ${ }^{3}$ NOAA/NWS/NCEP/Climate Prediction Center, College Park, Maryland, USA. ${ }^{4}$ State Key Laboratory of Earth Surface Processes and Resource Ecology, Beijing Normal University, Beijing, China. *email: tsengyh@ntu.edu.tw 


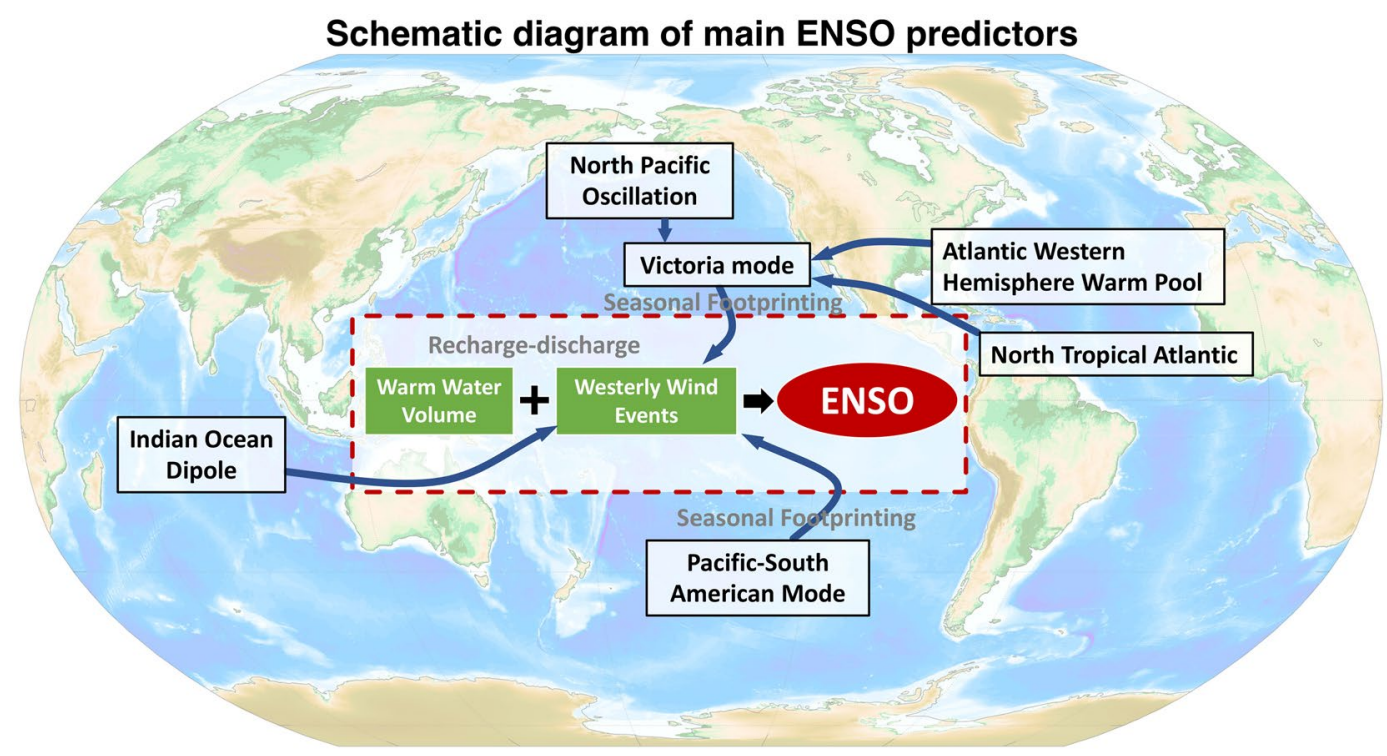

Figure 1. Schematic diagram of main ENSO predictors. The topographical mapping is based on 2-Minute Gridded Global Relief Data (ETOPO2) topography and generated using Matlab R2018b. The Matlab script (https://www.asu.cas.cz/ bezdek/vyzkum/rotating_3d_globe/index.php\#1b) is provided from Bezdek and Sebera $(2013)^{69}$.

increasing 6- to 10-month lead prediction skill beyond the SPB and to explain the dynamics behind the model. This improvement was especially noticeable in the first 2 decades of the $21^{\text {st }}$ century.

\section{Results}

Impact of extratropical atmospheric forcing on ENSO. Previous studies suggested that the extratropical atmospheric forcing is mostly a stochastic process ${ }^{16,17,33}$. However, some recent observational and modeling studies have suggested that the atmospheric variability outside the tropical Pacific has a significant influence on the onset of ENSO events, including the impact of atmospheric variability over the North Pacific ${ }^{16-20,27,34-36}$ and the South Pacific ${ }^{37-41}$. Signals in these extratropical atmospheric variabilities have been found to be useful as a major precursor for ENSO occurrence ${ }^{16,28,29,36,38,41,42}$.

Figure 2 shows the correlations of winter (November-March) sea surface temperature (SST) and SLP anomalies with the Niño3.4 index (defined as the averaged SST anomalies (SSTAs) over the region $170^{\circ}-120^{\circ} \mathrm{W}, 5^{\circ} \mathrm{S}-$ $5^{\circ} \mathrm{N}$ ) 1 year later. A significant SLPA precursor signal appeared in both the North and South Pacific. The SLPA precursor signal and corresponding SSTAs in the North Pacific presented a typical North Pacific Oscillation (NPO)-like pattern ${ }^{43,44}$, a north-south dipole of SLPAs, whereas the SLPAs and SSTAs in the South Pacific show a pattern similar to the Pacific-South American pattern (PSA) ${ }^{45}$, characterized by a wave-like pattern of SLPAs. To identify the major impact of the extratropical ENSO precursors, the impacts of these two dipole modes over the North and South Pacific can be combined to construct an ENSO predictor according to extratropical teleconnection $\left(E P_{E X}\right)$ (see Methods).

Figure $3 a$ illustrates the power spectrum of unfiltered $E P_{E X}$ index anomalies that were calculated via Fast Fourier Transform (green curve). We note that the $E P_{E X}$ index can be separated into two distinct time scales. The longer time scale is dominated by interannual variability with periods varying from 12 months to 7 years ${ }^{46,47}$. The other time scale exhibits higher frequency with a period of less than 12 months and it was associated with midand high-latitude stochastic variability ${ }^{16,17,33}$. To remove the high-frequency component and maintain the interannual extratropical variability, an Ensemble Empirical Mode Decomposition (EEMD) (see Methods) is applied to decompose the $E P_{E X}$ index with different frequencies. The $\mathrm{IMF}_{1-5}$ of $E P_{E X}$ is composed of high frequencies (not shown) and the $\mathrm{IMF}_{6-10}$ of $E P_{E X}$ exhibits a lower frequency with a period from 12 months to 7 years (blue curve in Fig. 3a). The lead-lag correlation of the monthly EEMD filtered and unfiltered $E P_{E X}$ index, respectively, with the monthly Niño34 index is shown in Fig. 3b. For lead times of 6-10 months, the EEMD filtered (unfiltered) $E P_{E X}$ index shows a significant correlation with the Niño34 index, with a peak at a lead time of approximately 9 (7) months $^{29}$. The maximum correlation coefficient between the Niño34 index and the EEMD filtered $E P_{E X}(0.53)$ is clearly larger than that of the unfiltered $E P_{E X}(0.29)$. The relationship between ENSO and extratropical forcing is significant on the annual-to-interannual time scales, suggesting a potential of the extratropics to enhance the predictability of ENSO. Moreover, the impact of extratropical forcing varies strongly with seasons. The most significant impact of extratropical forcing on the ENSO is in MAM (Fig. S1), consistent with the time scale discussed above.

To further demonstrate the impact of extratropical atmospheric variability on the ENSO variability, the lag correlations of SSTAs and SLPAs with the monthly EEMD filtered and unfiltered $E P_{E X}$ index are shown in Fig. 4. The lag correlation patterns of SSTAs and SLPAs are both similar to the SSTAs and SLPAs that are associated with $\mathrm{ENSO}^{28}$, and the relationship is stronger for the EEMD filtered $E P_{E X}$ than for the unfiltered $E P_{E X}$. These results 


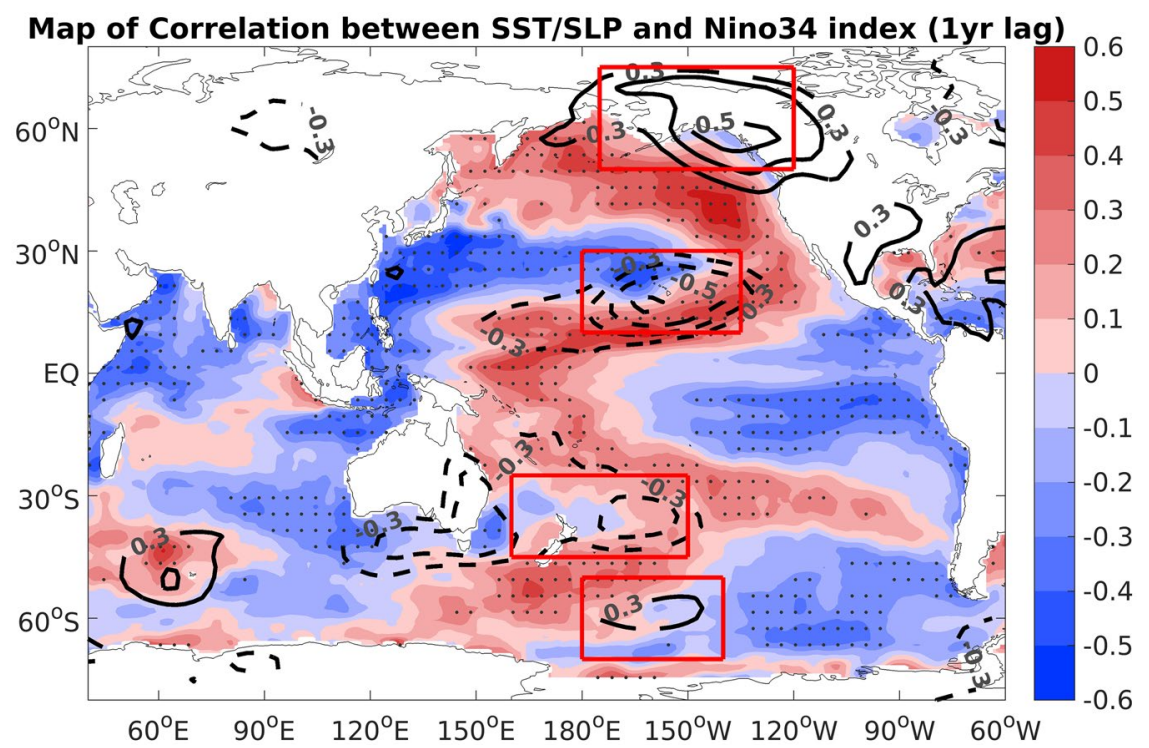

Figure 2. Correlation map of boreal winter (November-March) SST (shading) and SLP (contours) anomalies with the Niño3.4 index during the following boreal winter. The black dots indicate the correlation of SSTAs exceeding a $90 \%$ confidence level using a t-test. The SLPAs with correlations significant above the $90 \%$ confidence level are also shown. The four red boxes (from top to bottom: $175^{\circ}-120^{\circ} \mathrm{W}, 50^{\circ}-75^{\circ} \mathrm{N}$ and $180^{\circ}-$ $135^{\circ} \mathrm{W}, 10^{\circ}-30^{\circ} \mathrm{N}$ and $160^{\circ} \mathrm{E}-150^{\circ} \mathrm{W}, 25^{\circ}-45^{\circ} \mathrm{S}$ and $180^{\circ}-140^{\circ} \mathrm{W}, 50^{\circ}-70^{\circ} \mathrm{S}$ ) are used to defined the extratropical forcing index $\left(E P_{E X}\right)$.
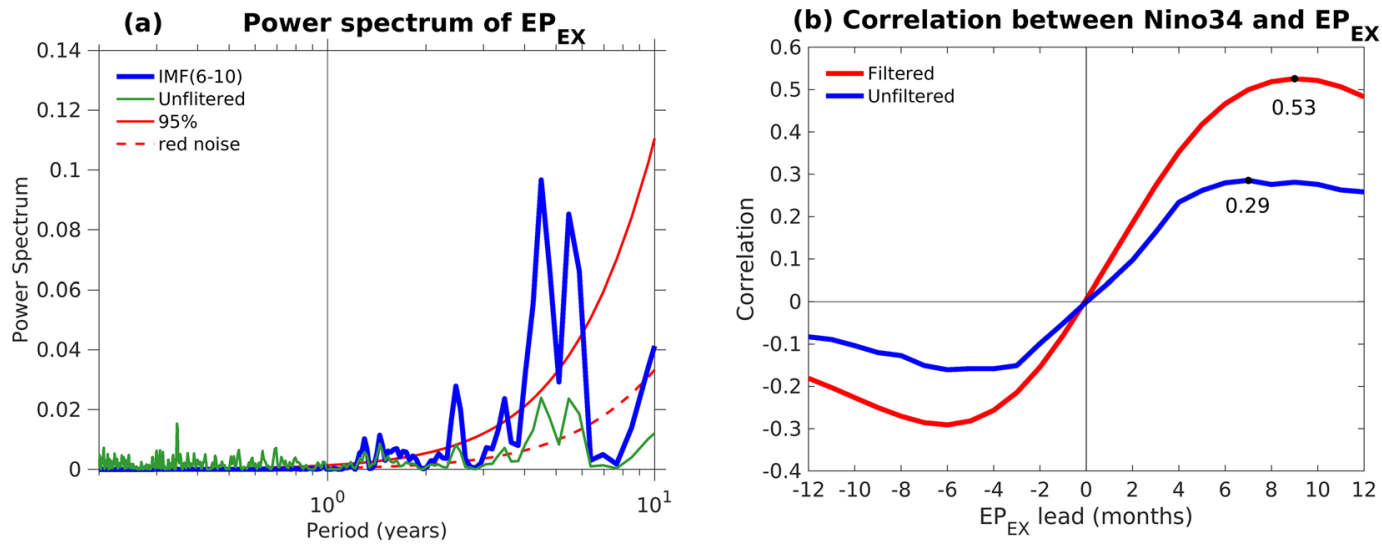

Figure 3. (a) Power spectrum analysis of the unfiltered (green curve) and EEMD filtered ( $\mathrm{IMF}_{6-10}$; blue curve) $E P_{E X}$. Red noise (dashed red curve) and the $95 \%$ statistical confidence (solid red lines) for the $\mathrm{IMF}_{6-10}$ of $E P_{E X}$ are indicated. The vertical black line represents a period of 12 months. (b) Lead-lag correlation of Niño3.4 index with the unfiltered (blue curve) and EEMD filtered (red curve) $E P_{E X}$. Maximum correlations are labeled (black dots).

support the previous arguments that the NPO-like or PSA-like atmospheric pattern associated with surface wind fields over the North or South Pacific can modulate SSTAs in the tropical Pacific and alter the ENSO evolution, as shown in the evolution of Fig. $4 \mathrm{a}-\mathrm{d}$ (also e-h) $)^{16,17,27,29,36,41}$.

The subtropical SST pattern in the Northern Hemisphere is the typical footprinting of the Victoria mode (also called the Pacific meridional mode, PMM, for a regional domain) ${ }^{48-50}$ while the quadrupole SST pattern in the Southern Hemisphere is called the South Pacific meridional mode ${ }^{40,41,51}$. These SST patterns may persist until boreal summer (hereafter, the seasons referred to are those of the Northern Hemisphere) and subsequently increase the zonal SST gradient across the western-central tropical Pacific and then strengthen the anomalous westerlies (easterlies) along the equatorial Pacific to initiate an El Niño (La Niña) event ${ }^{29,41}$ (see the evolution in Fig. 4b-c,f-g, respectively). Finally, the equatorial Pacific SSTAs reach the peak as an ENSO event with a corresponding west-east dipole of SLPAs (called Southern Oscillation) after about 8 months, consistent with the lead-lag relationship in Fig. $3 \mathrm{~b}\left(E P_{E X} \text { leads Niño34 index by } 6-10 \text { months }\right)^{29}$. These results support that the extratropical teleconnection can be an important precursor to trigger ENSO events and to potentially improve the ENSO predictability, specifically beyond the time scale of SPB. 


\section{Map of Correlation between SST/SLP and EP EX $_{\text {. }}$}
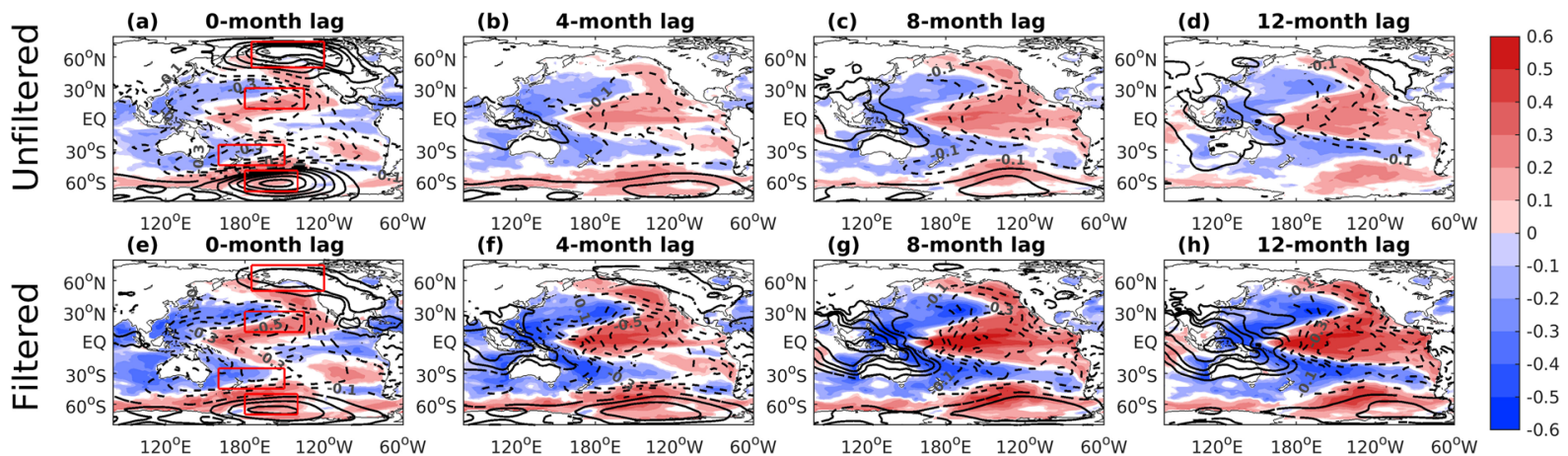

Figure 4. Correlations of the SST (shading) and SLP (contours) anomalies based on the (a-d) unfiltered and (e-h) EEMD filtered $E P_{E X}$ at different lag time (SST and SLP anomalies lag $\left.E P_{E X}\right)$. Only the correlations significant at or above the $95 \%$ confidence level are shown.

Predicting the ENSO beyond the Spring Predictability Barrier (SPB). The WWV and WWEs/ EWSs associated with key tropical Pacific dynamics have been considered to be essential processes for the ENSO occurrence ${ }^{6,23,24}$. However, the extratropical ocean-atmosphere interaction commonly plays an active role in the onset of ENSO events. To demonstrate these key processes in enhancing the prediction skill, we constructed a multivariate linear regression model based on the tropical dynamics and extratropical ocean-atmosphere interaction, as discussed in the Methods. For example, a 6-month lead multivariate linear regression model can be constructed as follows:

$$
E P M(t+6 \text { month })=\frac{\sigma_{O}}{\sigma_{P}}\left(0.43 E P_{W W V}(t)+0.22 E P_{O A}(t)+0.18 E P_{E X}(t)\right)
$$

Figure 5a shows a 3-month running mean time series of the monthly EPM (red line) using the 6-month lead linear regression model overlaid with the observed 3-month running mean Niño34 index (blue line). The correlation between predicted and observed Niño34 index was significant $(R=0.70)$ from 1981 to 2018. This 6-month lead hindcast skill was quantitatively similar to that based on the tropical condition only (Fig. $5 \mathrm{c}$ ) and superior to that based on the WWV index ( $R=0.57$ in Fig. $5 \mathrm{~d})$. The WWV index was defined as the volume of water above $20^{\circ} \mathrm{C}$ isotherm in the equatorial Pacific region $\left(5^{\circ} \mathrm{S}-5^{\circ} \mathrm{N}, 120^{\circ} \mathrm{E}-80^{\circ} \mathrm{W}\right)$.

For the 6-month lead prediction, the relative contributions of the tropical dynamics and the extratropical influence on the $E P M$ suggested the tropical dynamics associated with WWV and WWEs/EWSs $\left(E P_{W W V}+E P_{O A}\right)$ can capture most of the ENSO events (blue curve in Fig. 5b). The extratropical atmospheric influence $\left(E P_{E X}\right)$, in addition, can further provide useful information to enhance the hindcast skill (red curve in Fig. 5b). However, the improvement was limited, as expected. The $E P_{E X}$ leads $E P_{W W V}+E P_{O A}$ by about 2-3 months. The longer lead-time of the extratropical precursors suggests that the hindcast skill improvement is beyond 6-months, and thus potentially reduces the constraint of SPB.

To further examine the hindcast skill of EPM, we calculated the correlation and the RMSEs with different lead times in Table 1. Here, the EPM based on tropical dynamics only is presented as $E P M_{T D}$, and the $E P M$ considering tropical and extratropical precursors together is presented as $E P M_{T D+E X}$. For all lead-time hindcast (6-month and longer), the $E P M_{T D+E X}$ had higher hindcast skill in terms of correlation and RMSE measurements than $E P M_{T D}$ and WWV index. The correlation of $E P M_{T D+E X}$ was 0.65 (0.61) for an 8-month (10-month) lead, while the corresponding correlation was only $0.61(0.52)$ for $E P M_{T D}$ and $0.51(0.44)$ for WWV index. The RMSE skill also suggested that the hindcast Niño34 index based on $E P M_{T D+E X}$ was generally better than that based on either $E P M_{T D}$ or the WWV index.

We also computed the percent correct metric, which is defined as the fraction of the observed events that are correctly predicted, in Table 1 to quantify the robustness of EPM for predicting ENSO events. Since 1980, the $E P M_{T D+E X}$ with 6-month lead was $92 \%$ percent correct for El Niño and $86 \%$ percent correct for La Niña. The missed 1987/1988 El Niño, which was a double-dip El Niño after the 1986/87 El Niño event, was reinforced by the strong and uninterrupted WWEs with decaying heat content in the central tropical Pacific. For the missed 1995/96 La Niña, no significant EWSs and enhanced heat content exist with an unfavorable extratropical contribution during the developing phase. The missed 2005/06 La Niña was a weak event that was associated with poorly pre-conditioned WWV and weak EWSs.

The false alarm rate metric, defined as the fraction of the predicted events that do not actually occur, is also shown in Table 1. Generally, the performance of $E P M_{T D+E X}$ was better than others in percent correct and false alarm metrics. The improvement in the hindcast skill of $E P M_{T D+E X}$ was more significant for false alarms, but it only slightly increased the skill of the percent correct for $E P M_{T D+E X}$. This is because the evolution of accumulated $W W V$ is necessary for an ENSO event, and the prediction models based on equatorial heat content $\left(E P M_{T D+E X}\right.$, $E P M_{T D}$, and WWV index) easily capture the occurrence of an ENSO event using the existing WWV signal. However, the evolution of an ENSO event does not solely rely on the WWV condition, and other factors, e.g. 


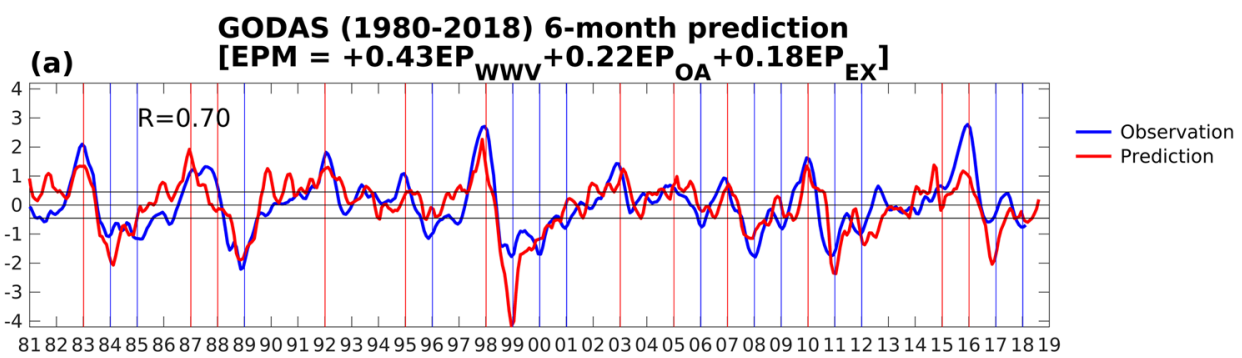

(b)

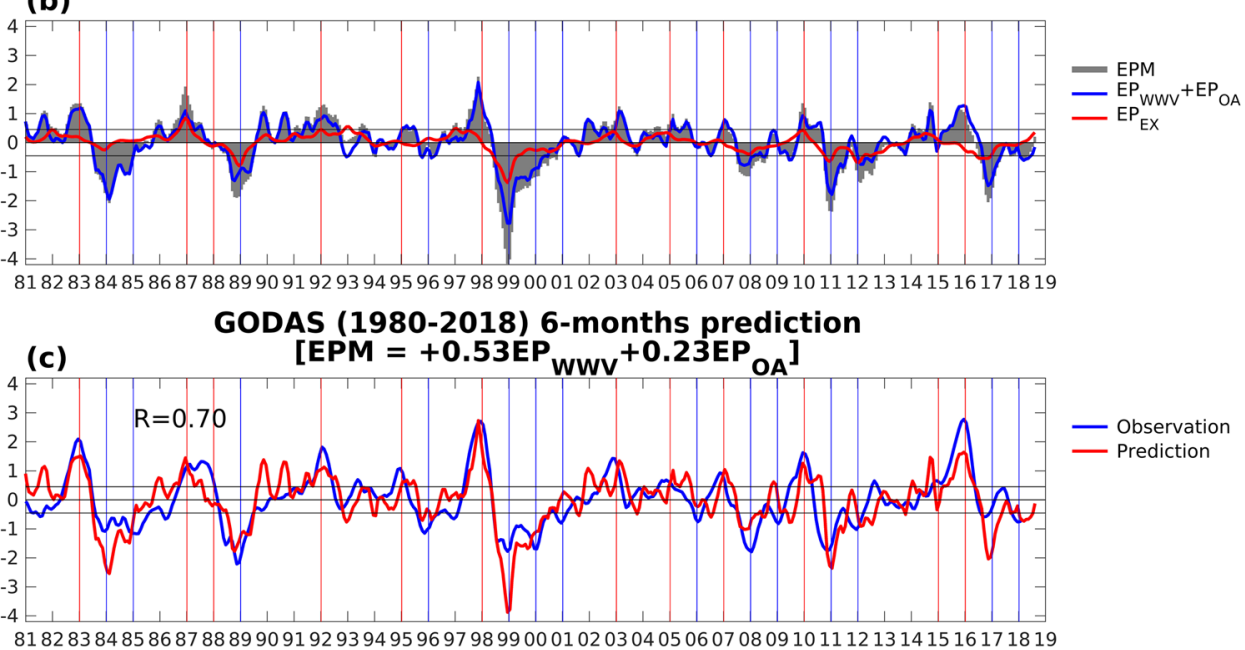

(d) [Predicted Nino34 $=+0.51 \mathrm{WWV}]$

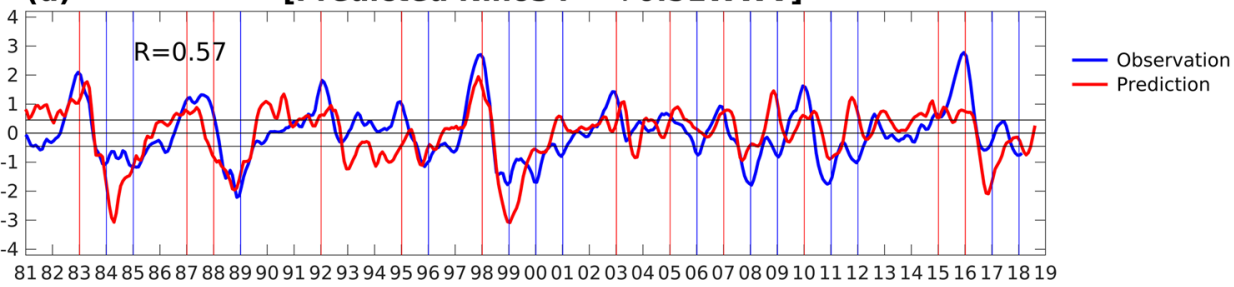

Figure 5. The 3-month running mean time series of the predicted Niño3.4 index (red line) generated by the 6-month lead regression model based on (a) the tropical and extratropical precursors together (c) the tropical dynamics ( $E P_{W W V}$ and $E P_{O A}$ only) and (d) WWV index overlaid with the observed Niño3.4 index (blue line). The vertical lines represent the peak year of El Niño events (red lines) and La Niña events (blue lines). (b) The time series of predicted Niño3.4 index contributed by $E P M$ (grey shading), $E P_{W W V}+E P_{O A}$ (blue curve) and $E P_{E X}$ (red curve).

extratropical forcing, are also important to determine the occurrence of an ENSO event. That is why the hindcast skill of the false alarm rate can be improved significantly when the tropical and extratropical precursors are all considered in $E P M\left(E P M_{T D+E X}\right)$, compared with that only the tropical dynamics are included in $E P M\left(E P M_{T D}\right)$.

EPM and hindcast skill in different prediction lead time. Hindcast skill is lower with a longer prediction lead time ${ }^{4}$. To quantify the influence of the tropical and extratropical precursors on the lead-time, we further analyzed the correlation and RMSE between the observed 3-month running mean and the predicted Niño34 index based on the WWV index only, tropical dynamics only $\left(E P M_{T D}\right)$, or tropical and extratropical precursors together $\left(E P M_{T D+E X}\right)$ with different lead-times (Fig. 6a,b). When we only consider the WWV index, the best hindcast skill appeared in the 5-month lead, which is consistent with the role of equatorial heat content in the recharge-discharge process ${ }^{9,52}$. If both of the WWV propagation and the ocean-atmosphere coupled feedback are included $\left(E P M_{T D}\right)$, the hindcast skill significantly increases for all lead times, especially for 1- to 6-month leads. For the $E P M$ proposed here $\left(E P M_{T D+E X}\right)$, the hindcast skill further increases with 6- to 10-month leads because of the extratropical precursors, indicating that including the extratropical influence can significantly improve the ENSO forecast skill at a lead time of longer than 6 months. Moreover, the coefficients of $E P_{W W V}$ (blue bars), $E P_{O A}$ (red bars), and $E P_{E X}$ (yellow bars) shown in Fig. $6 \mathrm{c}$ confirm the relative contributions of each predictor. For 1- to 3 -month leads, the hindcast skill is mainly contributed by the ocean-atmosphere coupled feedback because the zonal surface wind change is almost simultaneous with the change of the Niño34 index, which is a typical feature of the Bjerknes feedback for the growth of ENSO events $s^{6,7,9,53}$. The contribution of the ocean-atmosphere coupled 


\begin{tabular}{|c|c|c|c|c|c|c|c|c|c|c|c|c|}
\hline \multirow[b]{2}{*}{ Lead time } & \multicolumn{3}{|c|}{$\begin{array}{l}\text { Percent correct (\%) } \\
\text { El Niño (La Niña) }\end{array}$} & \multicolumn{3}{|c|}{$\begin{array}{l}\text { False alarm rate (\%) } \\
\text { El Niño (La Niña) }\end{array}$} & \multicolumn{3}{|l|}{ Correlation } & \multicolumn{3}{|l|}{ RMSE $\left({ }^{\circ} \mathrm{C}\right)$} \\
\hline & $E P M_{T D+E X}$ & $E P M_{T D}$ & WWV & $E P M_{T D+E X}$ & $E P M_{T D}$ & WWV & $E P M_{T D+E X}$ & $E P M_{T D}$ & WWV & $E P M_{T D+E X}$ & $E P M_{T D}$ & WWV \\
\hline Six-month & $92(86)$ & $92(79)$ & $83(71)$ & $39(14)$ & $39(21)$ & $47(23)$ & 0.70 & 0.70 & 0.57 & 0.70 & 0.70 & 0.84 \\
\hline Eight-month & $83(79)$ & $83(64)$ & $75(64)$ & $38(15)$ & $50(36)$ & $50(36)$ & 0.65 & \begin{tabular}{|l|}
0.61 \\
\end{tabular} & 0.51 & 0.76 & 0.80 & 0.90 \\
\hline Ten-month & $83(71)$ & $75(71)$ & $75(64)$ & $38(17)$ & $50(41)$ & $47(31)$ & 0.61 & 0.52 & 0.44 & 0.80 & 0.89 & 0.96 \\
\hline
\end{tabular}

Table 1. The hindcast skills according to percentage correct, correlation, and RMSE between 3-month running mean observed and predicted Niño34 index based on the WWV index only, tropical dynamics only $\left(E P M_{T D}\right)$, tropical and extratropical precursors together $\left(E P M_{T D+E X}\right)$ with different lead-times for the period of 19802018. The percent correct is defined as the fraction of the observed events which are correctly predicted. The false alarm is defined as the fraction of the predicted events actually do not occur. The perfect score is $100 \%$ and $0 \%$ for percent correct and false alarm rate, respectively.
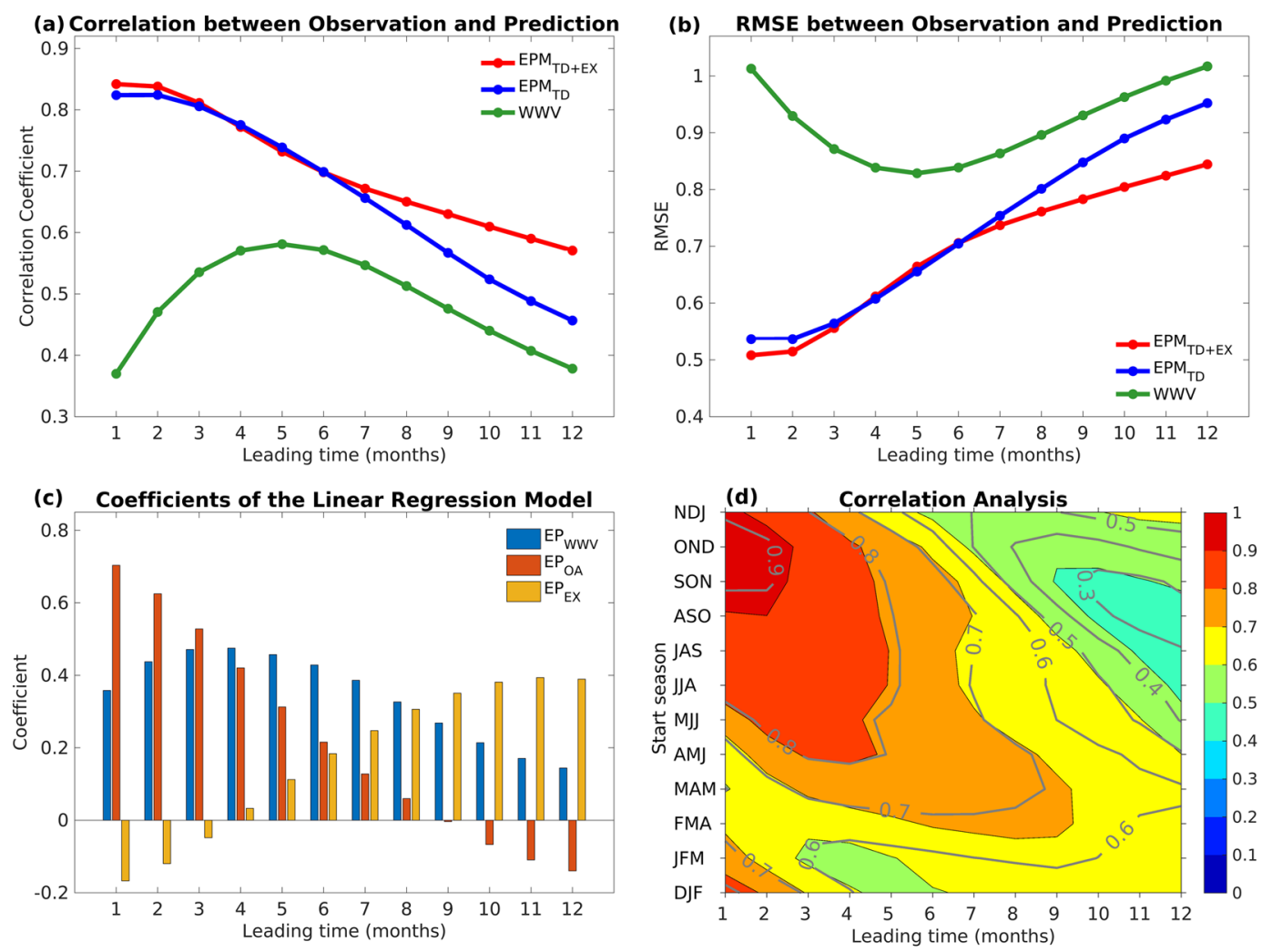

Figure 6. (a) Correlation and (b) RMSE between 3-month running mean observed and predicted Niño34 index based on the WWV index only (green curve), tropical dynamics only $\left(E P M_{T D}\right.$; blue curve), tropical and extratropical precursors together $\left(E P M_{T D+E X}\right.$; red curve) with different lead-times. (c) Coefficients of the multivariate linear regression model contributed by $E P_{W W V}$ (blue bars), $E P_{O A}$ (red bars) and $E P_{E X}$ (yellow bars) with different leading times. (d) Correlation between 3-month running mean observed and predicted Niño3.4 index based on $E P M_{T D+E X}$ (shadings), $E P M_{T D}$ (contours) as a function of start month and lead time.

feedback decreases linearly with an increased lead-time. However, the contribution of eastward-propagating WWV reaches its maximum at a 3-5 months lead because the WWV propagation signal in the central Pacific leads the Niño34 index by $3-4$ months ${ }^{23}$.

In contrast to the tropical precursors, the extratropical precursors have the largest contribution, with an 8 - to 10 -month lead. Because the lead-time extends over 6-months, the influence of the tropical dynamics is decreased with increased impacts of the extratropical precursors over both the North and South Pacific. We note that the coefficients of $E P_{E X}$ are negative in the 1- and 2-month leads, which are possibly caused by the positive feedback between the PMM and ENSO. This result indicates that the PMM can trigger the central Pacific ENSO events ${ }^{15}$ while, on the interannual timescales ${ }^{54}$, it can also be enhanced from the tropical forcing. Therefore, extratropical atmosphere forcing may trigger ENSO events by increasing the zonal SST gradient across the western-central tropical Pacific and then modulate the anomalous westerlies along the equatorial Pacific. Thus, the extratropical teleconnection can effectively improve ENSO prediction with 8- to 10-month leads. 
(a) Correlation between Observation and Prediction

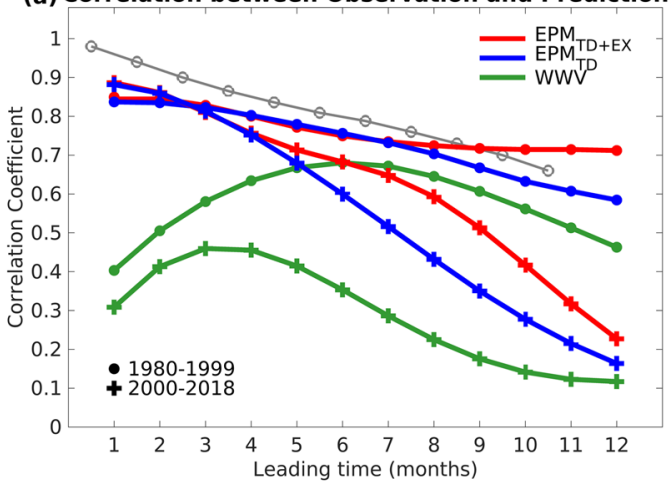

(c) Coefficients of Regression Model (1980-1999)

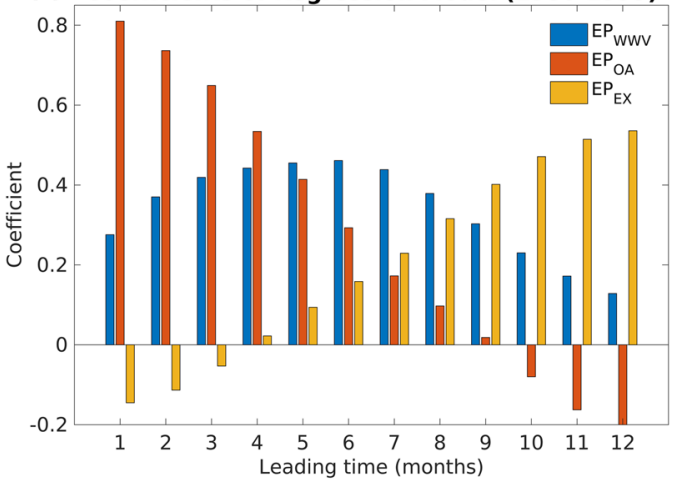

(b) Correlation between Nino34 and EP

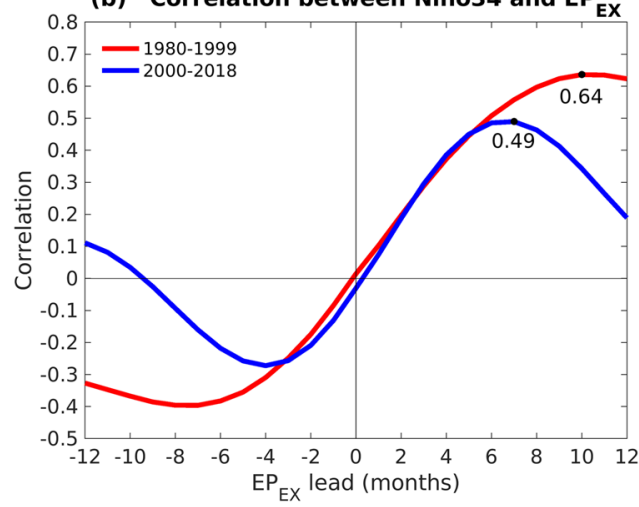

(d) Coefficients of Regression Model (2000-2018)

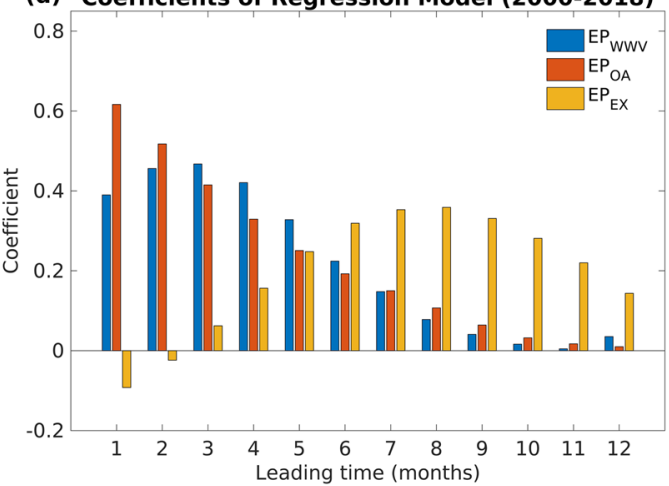

Figure 7. (a) Correlation between 3-month running mean observed and predicted Niño34 index based on the WWV index only (green curve), tropical dynamics only $\left(E P M_{T D}\right.$; blue curve), tropical and extratropical precursors together $\left(E P M_{T D+E X}\right.$; red curve) with different lead-times during 1980-1999 (dot-markers) and 2000-2018 (cross-markers). The prediction result of Clarke and Van Gorder (2003) based on WWV and IndoPacific winds for the period 1981-2001 is presented as grey curve with circle-markers. (b) Lead-lag correlation of Niño3.4 index with the EEMD filtered $E P_{E X}$ during 1980-1999 (red curve) and 2000-2018 (blue curve). Maximum correlations are labeled (black dots). (c,d) Show the coefficients of the multivariate linear regression model contributed by $E P_{W W V}$ (blue bars), $E P_{O A}$ (red bars) and $E P_{E X}$ (yellow bars) with different leading times during 1980-1999 and 2000-2018, respectively.

Figure $6 \mathrm{~d}$ shows the correlation between the observed and predicted Niño34 index based on $E P M_{T D+E X}$ and $E P M_{T D}$ as a function of start month and lead time. Overall, when the hindcast lead time is less than 6-month, the prediction starting in boreal spring (March, April, and May: MAM) had the lowest correlation while that starting in boreal summer (JJA) tended to have the greatest hindcast skills, i.e., the typical SPB. We note that the prediction skill based on $E P M_{T D+E X}$ (shading) showed a higher correlation than that based on $E P M_{T D}$ (contours), specifically when the prediction started in MAM and the lead time was longer than 7-month. The SPB of ENSO events were mainly generated by a strong seasonal modulation of the growth rate $^{55}$, indicating the difficulty in overcoming the SPB when only the tropical dynamics are considered as a precursor. The long-lead relationship between the extratropics and ENSO variability could partially reduce the long-lasting concern of SPB in the ENSO prediction.

Previous studies found that the ENSO hindcast/forecast skill has been reduced for the first decade of the $21^{\text {st }}$ century $^{4,21}$. Figure 7a shows the correlation between the observed and predicted Niño3.4 index based on three different schemes of the linear regression model with different lead times during 1980-1999 (dot-markers) and 2000-2018 (cross-markers). The difference in the ENSO prediction skill before and after 2000 can be easily observed. The maximum lead time for the WWV index (green curves) before 2000 (6 months) was longer than that after 2000 (3 months), which is consistent with previous studies that the WWV lead time changed from 6-9 months in 1979-1999 to 3-4 months after $2000^{21,56}$. Moreover, the hindcast skill (correlation) between the observed Niño3.4 and WWV index was much higher before 2000, which is consistent with the decadal change since 2000 that was shown in previous studies ${ }^{21,23}$. For the prediction model based on the tropical dynamics only (blue curves), the correlation between observation and prediction during 1980-1999 is also much higher. The correlation was 0.76 from $1980-1999$ and only 0.60 from 2000-2018 with a 6-month lead, which is consistent with the decrease in the correlation between Niño3.4 and WWV indices after $2000^{21,56}$.

When the new prediction scheme $(E P M)$ was considered based on both the tropical dynamics and extratropical teleconnection (Fig. 7a, red curves), the hindcast skill was improved both before and after 2000. Although the hindcast skill was higher before 2000, the improvement in the hindcast skill was greater in 2000-2018 compared with that during 1980-1999. The relationship between the Niño3.4 index and extratropical forcing also decreased 
after 2000, as shown in Fig. 7b, where the maximum lead time for the $E P_{E X}$ index in 1980-1999 (10 months) is longer than that in 2000-2018 (7 months) and the corresponding correlation coefficient decreased from 0.64 to 0.49 after 2000 . However, compared with WWV, the change in the extratropical forcing was relatively small and the prediction lead-time stayed at more than 7 months, and there was an improvement in the prediction skill after 2000.

To further investigate the change of relative contribution in $E P M$, the coefficient of $E P_{W W V}$ (blue bars), $E P_{O A}$ (red bars), and $E P_{E X}$ (yellow bars) in different $E P M$ lead-times before and after 2000 is shown in Fig. $7 \mathrm{c}$,d. The maximum contribution of $E P_{W W V}$ occurred with a 6-month lead in 1980-1999 and with a 3-month lead in 20002018. For 1980-1999, the contribution of the propagation of WWV to the hindcast skill was greater than the contribution of the extratropical atmospheric variability before the 8-month lead. On the other hand, the contribution of the extratropical forcing in 2000-2018 was larger than the contribution of the propagation of WWV after a 6-month lead, indicating the increased importance of the extratropics in predicting ENSO after 2000. The hindcast skill is mainly contributed by the ocean-atmosphere-coupled feedback for a short prediction lead time (1- to 2-month), and the importance of the ocean-atmosphere-coupled feedback decreased linearly with increased prediction lead-time. These results suggest that the extratropical atmospheric precursors in both the North and South Pacific are important in predicting ENSO and can reduce the long-lasting concern about SPB in the first 2 decades of the $21^{\text {st }}$ century.

To compare our EPM with other ENSO prediction models using tropical precursors, the prediction results from Clarke and Van Gorder ${ }^{57}$ based on the WWV and Indo-Pacific winds for the period 1981-2001 are shown in Fig. 7a. For a short lead time, the hindcast skill of their model was higher than that of EPM because they added eastern equatorial Indian Ocean wind stress to include the propagating signal of equatorial winds. However, when the lead time was longer than 8 months, the contribution of extratropical atmospheric precursors was more significant and the hindcast skill of EPM was higher than the model presented by Clarke and Van Gorder ${ }^{57}$.

Extratropical signals have been suggested to improve the ENSO prediction. Boschat's regression model based on JFM tropical WWV and extratropical SST precursors achieved a higher correlation score than the model that uses the JFM tropical WWV and zonal wind stress only for 1979-2008 (0.72 compared to 0.61 correlation $)^{58}$. Our correlation score of the EPM prediction from JFM based on tropical dynamics only $\left(E P M_{T D}\right)$ and tropical and extratropical precursors together $\left(E P M_{T D+E X}\right)$ was 0.66 and 0.74 for 1980-2008, respectively, which is comparable with Boschat's results.

The hindcast correlation of statistical models in "IRI ENSO Forecast", presented on the International Research Institute for Climate and Society (IRI) website (https://iri.columbia.edu/our-expertise/climate/enso/), is further shown in Fig. S2 for 2002-2018. The hindcast skill of most statistical models was lower than the EPM either based on the tropical dynamics and extratropical ocean-atmosphere $\left(E P M_{T D+E X}\right)$ or based on the tropical dynamics only $\left(E P M_{T D}\right)$. Overall, the proposed $E P M$ combining the tropical dynamics and extratropical forcing significantly enhanced the ENSO prediction skill, particularly for a forecast with a long lead time. This suggests that the ENSO occurrences after 2000 may rely more on the ocean-atmospheric process resulting from the extratropical influence that was discussed earlier ${ }^{1,15}$.

The internal tropical dynamics, including the propagation of accumulated WWV via the recharge-discharge process and the ocean-atmosphere coupling, serve as a necessary precondition for the possible growth of ENSO events and they play a dominant role in the ENSO evolution ${ }^{1,14,23}$. Other remote precursors such as the extratropical atmosphere forcing are additional triggering forcing that could further suppress or enhance the final ENSO development through the equatorial ocean-atmosphere coupling ${ }^{1,10,23}$. When the sufficient preconditioned heat content exists at the equator, as determined by the tropical dynamics combined with the extratropical forcing, the tropical Pacific warming in Spring could develop into an ENSO event. However, the WWV was no longer a highly reliable precursor for ENSO after 2000 because of the La Niña-like background mean state and steeper equatorial thermocline tilt, which hampered the eastward propagation of $\mathrm{WWV}^{1,59,60}$. Thus, the role of WWV decreased and the ENSO prediction skill also declined. Some studies suggested that the variability of North Pacific atmosphere became more effective at initiating El Niño events after $1990 \mathrm{~s}^{15,61}$. Moreover, the variance of the PMM associated with extratropical atmosphere forcing will increase in a warmer mean climate state ${ }^{62}$. These results supported the increasing importance of the extratropical precursors in predicting ENSO for the first 2 decades of the $21^{\text {st }}$ century and in a global warming situation.

\section{Data and Methods}

Observation and reanalysis data. In this study, several reanalysis datasets were used in constructing the statistical prediction model. Data from 1980 to the present were used. The ocean temperature data used in this analysis were the pentad global ocean data assimilation system (GODAS) on a $1 / 3^{\circ}$ latitude $\times 1.0^{\circ}$ longitude global grid $^{63}$. The SST was defined as the temperature of the first layer of the ocean (taken at 5-m depth). The near-surface wind data (0.995-sigma level) and sea level pressure data from the National Centers for Environmental Prediction and the National Center for Atmospheric Research (NCEP-NCAR) reanalysis project ${ }^{64}$ on a $2.5^{\circ} \times 2.5^{\circ}$ horizontal grid resolution were used to analyze the ocean-atmosphere coupling and extratropical atmospheric variability teleconnection. The anomalies here are based on the climatology from 1980 to 2018. $E P_{W W V}, E P_{O A}$, and $E P_{E X}$ were estimated using pentad data (5-day average) and then averaged monthly to build the multivariate linear regression model. All comparisons are made on a monthly time scale.

Definition of ENSO events. In this study, the El Niño (La Niña) was defined as an event with a 3-month running averaged Niño34 index that was greater than half a standard deviation (smaller than negative half a standard deviation). We note that some of the weak ENSO events defined here are slightly different from the definition of the Climate Prediction Center (CPC) (https://origin.cpc.ncep.noaa.gov/products/analysis_monitoring/ ensostuff/ONI_v5.php) because different datasets and different periods of the climatological mean are used. We 
chose the observed ENSO events based on the consensus of the definitions here and by the CPC. During the analysis period, there were 12 El Niño events (1982/83, 1986/87, 1987/88, 1991/92, 1994/95, 1997/98, 2002/03, 2004/05, 2006/07, 2009/10, 2014/15, and 2015/16) and 14 La Niña events (1983/84, 1984/85, 1988/89, 1995/96, 1998/99, 1999/00, 2000/01, 2005/06, 2007/08, 2008/09, 2010/11, 2011/12, 2016/17, and 2017/18).

ENSO prediction model. The ENSO prediction model (EPM) was built as follows:

$$
E P M(t+\phi)=\frac{\sigma_{O}(m)}{\sigma_{P}(m)}\left(\beta_{1} E P_{W W V}(t)+\beta_{2} E P_{O A}(t)+\beta_{3} E P_{E X}(t)\right)
$$

The first two terms on the right-hand side are called "tropical dynamics", including the predictors according to the propagation of WWV in the central Pacific $\left(E P_{W W V}\right)$ and the ocean-atmosphere feedback $\left(E P_{O A}\right)$; the third term, $E P_{E X}$, is called the extratropical atmosphere forcing term. $E P_{W W V}, E P_{O A}$, and $E P_{E X}$ were normalized before inputting into the linear regression model. The coefficients $\beta_{1}, \beta_{2}$, and $\beta_{3}$ were derived from the multivariate linear regression analysis, and they indicate the linear association between the predictors and observations, which may change with a different lead time. The monthly scaling function, $\frac{\sigma_{O}(m)}{\sigma_{P}(m)}$, based on the ratio between the standard deviation of the observation $\left(\sigma_{O}\right)$ and the prediction $\left(\sigma_{P}\right)$ for the month $(m)$ is applied to adjust the seasonal variance of prediction to observational variance (i.e., signal ratio). Then, a statistical prediction model is built to predict ENSO based on different lead times $(\varphi)$ to evaluate the hindcast skill.

Extratropical ENSO precursors index. The extratropical ENSO precursor index is represented by a combination of SLPAs that were averaged over the significant positive and negative correlation centers, as shown in Fig. 2. Four significant regions were chosen because the others are dependent ${ }^{28}$; the red boxes from top are $\mathrm{N} 1\left(175^{\circ}-120^{\circ} \mathrm{W}\right.$, $\left.50^{\circ}-75^{\circ} \mathrm{N}\right), \mathrm{N} 2\left(180^{\circ}-135^{\circ} \mathrm{W}, 10^{\circ}-30^{\circ} \mathrm{N}\right)$, S1 $\left(160^{\circ} \mathrm{E}-150^{\circ} \mathrm{W}, 25^{\circ}-45^{\circ} \mathrm{S}\right)$, and S2 $\left(180^{\circ}-140^{\circ} \mathrm{W}, 50^{\circ}-70^{\circ} \mathrm{S}\right)$. The index is defined as follows:

$$
E P_{E X}=\left(S L P A_{\mathrm{N} 1}-S L P A_{N 2}\right)+\left(S L P A_{S 2}-S L P A_{s 1}\right)
$$

An EEMD filter is performed to remove the high-frequency component while maintaining the interannual extratropical variability. In this study, the first ten IMFs are obtained for EEMD and only $\mathrm{IMF}_{6-10}$ of $E P_{E X}$, which exhibits a lower frequency with a period from 12 months to 7 years, is used to represent the interannual component of $E P_{E X}$.

Tropical ENSO precursors index. The tropical dynamics term EPM is constructed by a function of WWV in the central Pacific $\left[E P_{W W V}(t)\right]$ and the ocean-atmosphere feedback $\left[E P_{O A}(t)\right]^{23}$. The WWV function is defined based on the feature of eastward propagation WWV as follows:

$$
\begin{aligned}
E P_{W W V}(t)= & \alpha_{1} D 20 a_{180} \circ(t-5 \text { pentads })+\alpha_{2} D 20 a_{170}{ }^{\circ}(t-3 \text { pentads }) \\
& +\alpha_{3} D 20 a_{155^{\circ} W}(t)
\end{aligned}
$$

D20a is the $20^{\circ} \mathrm{C}$ thermocline depth (D20) anomaly that is averaged between $2^{\circ} \mathrm{S}$ and $2^{\circ} \mathrm{N}$ and $t$ is a given prediction initial time in pentad. The subscripts represent the longitudinal locations along the equator. The choice of longitudes and timings in $E P_{W W V}$ was based on the propagation of the eastward Kelvin wave at approximately $30^{\circ} /$ month $^{23}$. The weighting parameters $\alpha_{1} \sim a_{3}$ are defined as the difference between the climatological mean of D20 at $175^{\circ} \mathrm{E}$ and the climatological mean of D20 at these three longitudes. $\alpha_{1}, \alpha_{2}$ and $\alpha_{3}$ are 2.8, 9.2 and 28.1 used here, respectively.

The other term, $E P_{O A}(t)$, measures the positive feedback resulting from the interaction between the atmosphere and ocean at the equator. $E P_{O A}(t)$ reflects that the ocean-atmosphere coupled feedback can amplify or suppress the anomaly of $E P_{W W V}(t)$, according to the events of westerly wind events/easterly wind surges (WWEs/ EWSs). This coupled feedback is constructed as:

$$
E P_{O A}(t)=\operatorname{sign}\left(\operatorname{event}\left(t, w_{x}\right)\right) \cdot d H\left(t, E P_{W W V}\right)
$$

where $w_{x}$ represents the zonal surface wind anomalies over the region $180^{\circ}-155^{\circ} \mathrm{W}, 2^{\circ} \mathrm{S}-2^{\circ} \mathrm{N}$. The $E P_{O A}(t)$ includes two parts. The first part is to define the wind event (westerly or easterly anomalies) as follows:

$$
\text { event }\left(t, w_{x}\right)=\left\{\begin{array}{l}
\text { positive } w_{x} \text { in }[t-10 \text { pentads, } t] \\
\text { negative } w_{x} \text { in }[t-10 \text { pentads, } t]
\end{array}\right.
$$

The second part is to measure the modulation of the wind event on the change of WWV, which can amplify or suppress the development of the Bjerknes feedback. Here, we assume that $E P_{O A}(t)$ is active only when the $E P_{W W V}$ changes dramatically and the same sign wind events can be detected for more than 5 pentads ( 25 days) during a continuous period of 10 pentads (50 days), representing the consistent westerly or easterly anomalies. The modulation of the wind event is defined as:

$d H\left(t, E P_{W W V}\right)=\left\{\begin{array}{cl}\frac{\left|E P_{W W V}(t)-E P_{W W V}(t-5)\right|+\left|E P_{W W V}(t-5)-E P_{W W V}(t-10)\right|}{2}, & 5 \text { pentads } \leq \text { event }\left(t, w_{x}\right) \\ 0, & \text { event }\left(t, w_{x}\right)<5 \text { pentads }\end{array}\right.$ 
Ensemble empirical mode decomposition (EEMD). Empirical mode decomposition (EMD) is a method of breaking down signals into various components $s^{65}$. The decomposition is designed to seek the different intrinsic mode functions (IMFs) of oscillations from high-frequency to low-frequency based on local time scales. After extracting $M-1$ IMFs via EMD, the original signal can be reconstructed by superposing the obtained IMFs and the residual $\left(r_{M}\right)$ :

$$
X(t)=\sum_{m=1}^{M-1} \operatorname{IMF}_{m}(t)+r_{M}(t)
$$

A higher order of IMF (larger $m$ ) refers to a lower frequency component.

Ensemble EMD (EEMD) is an extension of the EMD ${ }^{66,67}$. The IMFs from EEMD are based on an average of EMD ensembles, and each EMD member has an added independent white noise with the same standard deviation. In contrast to many almost previous decomposition methods, the EEMD is empirical, intuitive, direct, and adaptive. Specifically, no pre-determined basis functions are required.

Using the EEMD as a low-pass filter is natural and it is more practical in real-time forecast than the conventional time filters. The potential end-point effect issue can be minimized. The end-point effect occurs at the beginning and end of the signal because there is no point before the first data point and after the last one to be considered $^{68}$. A modified linear extrapolation method ${ }^{66}$, where additional extrema are added to the ends of the data by linear extrapolation of the two maxima (minima) near the end point, is adopted to reduces the end-point effect.

\section{Data availability}

The data supporting the findings of this study are available within the article. Any other data are available from the corresponding author upon request.

Received: 3 July 2019; Accepted: 18 November 2019;

Published online: 22 January 2020

\section{References}

1. Timmermann, A. et al. El Niño-Southern Oscillation complexity. Nature 559, 535 (2018)

2. Latif, M. et al. A review of the predictability and prediction of ENSO. J. Geophys. Res. Oceans 103, 14375-14393 (1998).

3. Barnston, A. G., Glantz, M. H. \& He, Y. Predictive Skill of Statistical and Dynamical Climate Models in SST Forecasts during the 1997-98 El Niño Episode and the 1998 La Niña Onset. Bull. Am. Meteorol. Soc. 80, 217-244 (1999).

4. Barnston, A. G., Tippett, M. K., L'Heureux, M. L., Li, S. \& DeWitt, D. G. Skill of Real-Time Seasonal ENSO Model Predictions during 2002-11: Is Our Capability Increasing? Bull. Am. Meteorol. Soc. 93, 631-651 (2011).

5. Tang, Y. et al. Progress in ENSO prediction and predictability study. Natl. Sci. Rev. 5, 826-839 (2018).

6. Jin, F.-F. An equatorial ocean recharge paradigm for ENSO. Part I: Conceptual model. J. Atmospheric Sci. 54, 811-829 (1997).

7. Jin, F. F. An equatorial recharge paradigm for ENSO. II: A stripped-down coupled model. J Atmos Sci 54, 830-8847 (1997).

8. Li, T. Phase transition of the El Niño-Southern Oscillation: A stationary SST mode. J. Atmospheric Sci. 54, 2872-2887 (1997).

9. Chen, H. C., Sui, C. H., Tseng, Y. H. \& Huang, B. H. An Analysis of the Linkage of Pacific Subtropical Cells with the RechargeDischarge Processes in ENSO Evolution. J. Clim. 28, 3786-3805 (2015).

10. Tseng, Y.-H., Ding, R. \& Huang, X. The warm Blob in the northeast Pacific - the bridge leading to the $2015 / 16 \backslash \mathrm{hspace} 0.167 \mathrm{emEl}$ Niño. Environ. Res. Lett. 12, 054019 (2017).

11. Vecchi, G. A. \& Harrison, D. E. Tropical Pacific Sea Surface Temperature Anomalies, El Niño, and Equatorial Westerly Wind Events. J. Clim. 13, 1814-1830 (2000).

12. McPhaden, M. J. Evolution of the 2002/03 El Niño*. Bull. Am. Meteorol. Soc. 85, 677-696 (2004).

13. Chiodi, A. M. \& Harrison, D. E. Equatorial Pacific Easterly Wind Surges and the Onset of La Niña Events. J. Clim. 28, 776-792 (2014).

14. Chen, H.-C., Sui, C.-H., Tseng, Y.-H. \& Huang, B. Combined Role of High- and Low-Frequency Processes of Equatorial Zonal Transport in Terminating an ENSO Event. J. Clim. 31, 5461-5483 (2018).

15. Yu, J.-Y. \& Fang, S.-W. The Distinct Contributions of the Seasonal Footprinting and Charged-Discharged Mechanisms to ENSO Complexity. Geophys. Res. Lett. 45, 6611-6618 (2018).

16. Vimont, D. J., Battisti, D. S. \& Hirst, A. C. The Seasonal Footprinting Mechanism in the CSIRO General Circulation Models. J. Clim. 16, 2653-2667 (2003)

17. Vimont, D. J., Wallace, J. M. \& Battisti, D. S. The Seasonal Footprinting Mechanism in the Pacific: Implications for ENSO. J. Clim. 16, 2668-2675 (2003).

18. Vimont, D. J., Alexander, M. \& Fontaine, A. Midlatitude Excitation of Tropical Variability in the Pacific: The Role of Thermodynamic Coupling and Seasonality. J. Clim. 22, 518-534 (2009).

19. Alexander, M. A., Vimont, D. J., Chang, P. \& Scott, J. D. The Impact of Extratropical Atmospheric Variability on ENSO: Testing the Seasonal Footprinting Mechanism Using Coupled Model Experiments. J. Clim. 23, 2885-2901 (2010).

20. Yu, J.-Y. \& Kim, S. T. Relationships between Extratropical Sea Level Pressure Variations and the Central Pacific and Eastern Pacific Types of ENSO. J. Clim. 24, 708-720 (2010).

21. McPhaden, M. J. A 21st century shift in the relationship between ENSO SST and warm water volume anomalies. Geophys. Res. Lett., 39 (2012)

22. Clarke, A. J. El Niño Physics and El Niño Predictability. Annu. Rev. Mar. Sci. 6, 79-99 (2014).

23. Tseng, Y. H., Hu, Z.-Z., Ding, R. Q. \& Chen, H. C. An ENSO prediction approach based on ocean conditions and ocean-atmosphere coupling. Clim. Dyn. 48, 2025-2044 (2017).

24. Fang, X.-H. \& Mu, M. Both air-sea components are crucial for El Niño forecast from boreal spring. Sci. Rep. 8, 10501 (2018).

25. Wen, C., Kumar, A., Xue, Y. \& McPhaden, M. J. Changes in Tropical Pacific Thermocline Depth and Their Relationship to ENSO after 1999. J. Clim. 27, 7230-7249 (2014).

26. Newman, M. \& Sardeshmukh, P. D. Are we near the predictability limit of tropical Indo-Pacific sea surface temperatures? Geophys. Res. Lett. 44, 8520-8529 (2017).

27. Ding, R., Li, J., Tseng, Y., Sun, C. \& Guo, Y. The Victoria mode in the North Pacific linking extratropical sea level pressure variations to ENSO. J. Geophys. Res. Atmospheres 120, 27-45 (2015).

28. Ding, R., Li, J., Tseng, Y., Sun, C. \& Xie, F. Joint impact of North and South Pacific extratropical atmospheric variability on the onset of ENSO events. J. Geophys. Res. Atmospheres 122, 279-298 (2017). 
29. Ding, R. et al. Relative contributions of North and South Pacific sea surface temperature anomalies to ENSO. J. Geophys. Res. Atmospheres, 2018JD030181, https://doi.org/10.1029/2018JD030181 (2019).

30. Ding, R. et al. Interdecadal change in the lagged relationship between the Pacific-South American pattern and ENSO. Clim. Dyn. 47, 2867-2884 (2016).

31. Park, J.-H., Kug, J.-S., Li, T. \& Behera, S. K. Predicting El Niño Beyond 1-year Lead: Effect of the Western Hemisphere Warm Pool. Sci. Rep. 8, 14957 (2018).

32. Ham, Y.-G., Kug, J.-S. \& Park, J.-Y. Two distinct roles of Atlantic SSTs in ENSO variability: North Tropical Atlantic SST and Atlantic Niño. Geophys. Res. Lett. 40, 4012-4017 (2013).

33. Barnett, T. P. et al. Origins of the midlatitude Pacific decadal variability. Geophys. Res. Lett. 26, 1453-1456 (1999).

34. Anderson, B. T. \& Maloney, E. Interannual Tropical Pacific Sea Surface Temperatures and Their Relation to Preceding Sea Level Pressures in the NCAR CCSM2. J. Clim. 19, 998-1012 (2006)

35. Yu, J.-Y., Kao, H.-Y. \& Lee, T. Subtropics-Related Interannual Sea Surface Temperature Variability in the Central Equatorial Pacific. J. Clim. 23, 2869-2884 (2010).

36. Anderson, B. T. Tropical Pacific sea-surface temperatures and preceding sea level pressure anomalies in the subtropical North Pacific. J. Geophys. Res. Atmospheres. 108 (2003).

37. Jin, D. \& Kirtman, B. P. Why the Southern Hemisphere ENSO responses lead ENSO. J. Geophys. Res. Atmospheres. 114 (2009).

38. Terray, P. Southern Hemisphere extra-tropical forcing: a new paradigm for El Niño-Southern Oscillation. Clim. Dyn. 36, 2171-2199 (2011).

39. Hong, L.-C. LinHo \& Jin, F.-F. A Southern Hemisphere booster of super El Niño. Geophys. Res. Lett. 41, 2142-2149 (2014).

40. Zhang, H., Clement, A. \& Di Nezio, P. The South Pacific Meridional Mode: A Mechanism for ENSO-like Variability. J. Clim. 27, 769-783 (2013)

41. Ding, R., Li, J. \& Tseng, Y. The impact of South Pacific extratropical forcing on ENSO and comparisons with the North Pacific. Clim. Dyn. 44, 2017-2034 (2015).

42. Larson, S. M. \& Kirtman, B. P. The Pacific Meridional Mode as an ENSO Precursor and Predictor in the North American Multimodel Ensemble. J. Clim. 27, 7018-7032 (2014).

43. Walker, G. \& Bliss, E. World weather V. Mem. R. Meteorol. Soc., 4, 53-84 (1932).

44. Rogers, J. C. Spatial Variability of Seasonal Sea Level Pressure and 500 mb Height Anomalies. Mon. Weather Rev. 109, 2093-2106 (1981).

45. Mo, K. C. Relationships between Low-Frequency Variability in the Southern Hemisphere and Sea Surface Temperature Anomalies. J. Clim. 13, 3599-3610 (2000).

46. Alexander, M. A. et al. The Atmospheric Bridge: The Influence of ENSO Teleconnections on Air-Sea Interaction over the Global Oceans. J. Clim. 15, 2205-2231 (2002)

47. Furtado, J. C., Di Lorenzo, E., Schneider, N. \& Bond, N. A. North Pacific Decadal Variability and Climate Change in the IPCC AR4 Models. J. Clim. 24, 3049-3067 (2010).

48. Bond, N. A., Overland, J. E., Spillane, M. \& Stabeno, P. Recent shifts in the state of the North Pacific. Geophys. Res. Lett., 30 (2003).

49. Chiang, J. C. H. \& Vimont, D. J. Analogous Pacific and Atlantic Meridional Modes of Tropical Atmosphere-Ocean Variability. J. Clim. 17, 4143-4158 (2004).

50. Chang, P. et al. Pacific meridional mode and El Niño-Southern Oscillation. Geophys. Res. Lett. 34 (2007).

51. Zhang, H., Deser, C., Clement, A. \& Tomas, R. Equatorial signatures of the Pacific Meridional Modes: Dependence on mean climate state. Geophys. Res. Lett. 41, 568-574 (2014).

52. McPhaden, M. J. Tropical Pacific Ocean heat content variations and ENSO persistence barriers. Geophys. Res. Lett. 30 (2003).

53. Bjerknes, J. Atmospheric teleconnections from the equatorial Pacific. Mon. Weather Rev. 97, 163-172 (1969).

54. Stuecker, M. F. Revisiting the Pacific Meridional Mode. Sci. Rep. 8, 3216 (2018).

55. Liu, Z., Jin, Y. \& Rong, X. A Theory for the Seasonal Predictability Barrier: Threshold, Timing, and Intensity. J. Clim. 32, 423-443 (2018).

56. Hu, Z.-Z. et al. On the Shortening of the Lead Time of Ocean Warm Water Volume to ENSO SST Since 2000. Sci. Rep. 7, 4294 (2017).

57. Clarke, A. J. \& Gorder, S. V. Improving El Niño prediction using a space-time integration of Indo-Pacific winds and equatorial Pacific upper ocean heat content. Geophys. Res. Lett. 30 (2003).

58. Boschat, G., Terray, P. \& Masson, S. Extratropical forcing of ENSO. Geophys. Res. Lett. 40, 1605-1611 (2013).

59. Hu, Z.-Z. et al. Weakened Interannual Variability in the Tropical Pacific Ocean since 2000. J. Clim. 26, 2601-2613 (2012).

60. Hu, Z.-Z., Kumar, A., Huang, B., Zhu, J. \& Ren, H.-L. Interdecadal variations of ENSO around 1999/2000. J. Meteorol. Res. 31, 73-81 (2017).

61. Yeh, S.-W., Wang, X., Wang, C. \& Dewitte, B. On the Relationship between the North Pacific Climate Variability and the Central Pacific El Niño. J. Clim. 28, 663-677 (2014).

62. Liguori, G. \& Lorenzo, E. D. Meridional Modes and Increasing Pacific Decadal Variability Under Anthropogenic Forcing. Geophys. Res. Lett. 45, 983-991 (2018).

63. Behringer, D. The Global Ocean Data Assimilation System (GODAS) at NCEP. Preprints, 11th Symp. on Integrated Observing and Assimilation Systems for Atmosphere, Oceans, and Land Surface, San Antonio, TX, Amer. Meteor. Soc., 3.3. Available online at http://ams.confex.com/ams/87ANNUAL/techprogram/paper_119541.htm (2007).

64. Kalnay, E. et al. The NCEP/NCAR 40-Year Reanalysis Project. Bull. Am. Meteorol. Soc. 77, 437-472 (1996).

65. Huang, N. E. et al. The empirical mode decomposition and the Hilbert spectrum for nonlinear and non-stationary time series analysis. Proc. R. Soc. Lond. Ser. Math. Phys. Eng. Sci. 454, 903-995 (1998).

66. Wu, Z. \& Huang, N. E. Ensemble Empirical Mode Decomposition: a Noise-Assisted Data Analysis Method. Adv. Adapt. Data Anal. 1, 1-41 (2009).

67. Wang, Y.-H., Yeh, C.-H., Young, H.-W. V., Hu, K. \& Lo, M.-T. On the computational complexity of the empirical mode decomposition algorithm. Phys. Stat. Mech. Its Appl. 400, 159-167 (2014).

68. Wang, H. \& Ji, Y. A Revised Hilbert-Huang Transform and Its Application to Fault Diagnosis in a Rotor System. Sensors 18, 4329 (2018).

69. Bezděk, A. \& Sebera, J. Matlab script for 3D visualizing geodata on a rotating globe. Comput. Geosci. 56, 127-130 (2013).

\section{Acknowledgements}

H.-C. Chen is supported by Taiwan Ministry of Science and Technology (107-2917-I-564-005) and U.S. NSF grant AGS-1813611. Y. H. Tseng is supported by the Ministry of Science and Technology (107-2611-M-002013-MY4 and 108-2111-M-002-006-MY3), Taiwan.

\section{Author contributions}

H.-C. Chen and Y.-H. Tseng designed the study and prepared the manuscript with inputs from Z.-Z. Hu and R. Ding. H.-C. Chen analyzed the data, prepared the figures and performed the model prediction. All authors discussed the results and commented on the manuscript. 


\section{Competing interests}

The authors declare no competing interests.

\section{Additional information}

Supplementary information is available for this paper at https://doi.org/10.1038/s41598-020-57853-7.

Correspondence and requests for materials should be addressed to Y.-H.T.

Reprints and permissions information is available at www.nature.com/reprints.

Publisher's note Springer Nature remains neutral with regard to jurisdictional claims in published maps and institutional affiliations.

(c) (i) Open Access This article is licensed under a Creative Commons Attribution 4.0 International License, which permits use, sharing, adaptation, distribution and reproduction in any medium or format, as long as you give appropriate credit to the original author(s) and the source, provide a link to the Creative Commons license, and indicate if changes were made. The images or other third party material in this article are included in the article's Creative Commons license, unless indicated otherwise in a credit line to the material. If material is not included in the article's Creative Commons license and your intended use is not permitted by statutory regulation or exceeds the permitted use, you will need to obtain permission directly from the copyright holder. To view a copy of this license, visit http://creativecommons.org/licenses/by/4.0/.

(C) The Author(s) 2020 